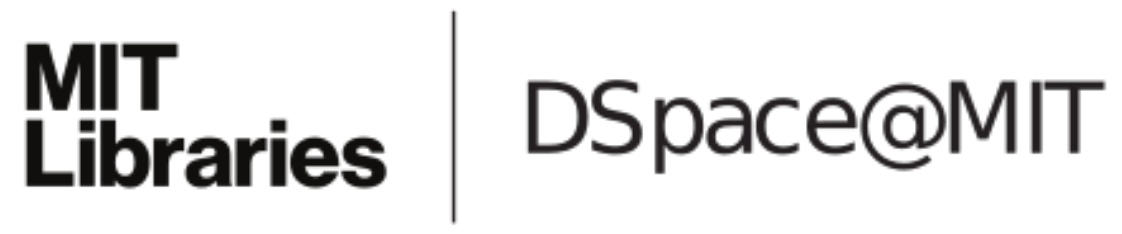

\author{
MIT Open Access Articles
}

\section{Tunable mixed-valence doping toward record electrical conductivity in a three-dimensional metal-organic framework}

The MIT Faculty has made this article openly available. Please share how this access benefits you. Your story matters.

Citation: Xie, Lilia S., et al. "Tunable mixed-valence doping toward record electrical conductivity in a three-dimensional metal-organic framework." Journal of the American Chemical Society 140, 24 (2018): p. 7411-14 doi 10.1021/JACS.8B03604 (C2018 Author(s)

As Published: 10.1021/JACS.8B03604

Publisher: American Chemical Society (ACS)

Persistent URL: https://hdl.handle.net/1721.1/126154

Version: Author's final manuscript: final author's manuscript post peer review, without publisher's formatting or copy editing

Terms of Use: Article is made available in accordance with the publisher's policy and may be subject to US copyright law. Please refer to the publisher's site for terms of use. 


\title{
Tunable Mixed-Valence Doping toward Record Electrical Conductivity in a Three-Dimensional Metal-Organic Framework
}

\author{
Lilia S. Xie, ${ }^{\dagger}$ Lei Sun, ${ }^{\dagger}$ Ruomeng Wan, ${ }^{\dagger}$ Sarah S. Park, ${ }^{\dagger}$ Jordan A. DeGayner, \\ Christopher H. Hendon, ${ }^{\S}{ }^{\circledR 0}$ and Mircea Dincă ${ }^{*}{ }^{\dagger}$ \\ ${ }^{\dagger}$ Department of Chemistry, Massachusetts Institute of Technology, 77 Massachusetts Avenue, Cambridge, Massachusetts 02139, \\ United States \\ ${ }^{\ddagger}$ Department of Chemistry, Northwestern University, Evanston, Illinois 60208, United States \\ ${ }^{\S}$ Materials Science Institute, Department of Chemistry and Biochemistry, University of Oregon, Eugene, Oregon 97403, United States
}

Supporting Information

\begin{abstract}
Partial oxidation of an iron-tetrazolate metal-organic framework (MOF) upon exposure to ambient atmosphere yields a mixed-valence material with single-crystal conductivities tunable over 5 orders of magnitude and exceeding $1 \mathrm{~S} / \mathrm{cm}$, the highest for a three-dimensionally connected MOF. Variable-temperature conductivity measurements reveal a small activation energy of $160 \mathrm{meV}$. Electronic spectroscopy indicates the population of midgap states upon air exposure and corroborates intervalence charge transfer between $\mathrm{Fe}^{2+}$ and $\mathrm{Fe}^{3+}$ centers. These findings are consistent with lowlying $\mathrm{Fe}^{3+}$ defect states predicted by electronic band structure calculations and demonstrate that inducing metal-based mixed valency is a powerful strategy toward realizing high and systematically tunable electrical conductivity in MOFs.
\end{abstract}

$\mathrm{E}$ lectrically conductive metal-organic frameworks (MOFs) are emerging as a class of porous materials of interest for diverse applications as well as for fundamental studies of charge transport in molecular materials. ${ }^{1}$ Several strategies for enhancing conductivities in MOFs have been demonstratedfor example, utilizing non-innocent ligands to introduce charge carriers, $^{2-7}$ minimizing energy differences between metal and ligand frontier orbital energies, ${ }^{8-10}$ and employing redox-active guest molecules in post-synthetic modification. ${ }^{11-13}$ Although mixed valency is a feature that has been observed in many conductive MOFs to varying degrees, ${ }^{14,15}$ studies that actively and systematically introduce mixed-valence motifs and correlate their effect on conductivity in this class of materials are lacking.

We reported previously that frameworks based on $\mathrm{Fe}^{2+}$ exhibit higher conductivities and lower activation energies compared to many other divalent transition metals across different structural families, likely due to hole doping with small amounts of $\mathrm{Fe}^{3+}$ in these frameworks. ${ }^{16}$ However, previous materials did not allow for systematic variation of the doping level, and thus the influence of $\mathrm{Fe}^{3+}$ sites was inferred indirectly. As such, we sought to develop additional $\mathrm{Fe}^{2+}$-based frameworks in order to ascertain the influence of metal-based mixed valency on transport properties and expand the range of conductivities accessible via this approach. In particular, we targeted frameworks with structural motifs such as infinite onedimensional secondary building units (SBUs) and relatively electropositive ligands that would reduce the activation barrier for charge transfer, thereby engendering low-energy charge transport pathways.

With this motivation, we studied the electronic properties of the $\mathrm{Fe}_{2}\left(\mathrm{H}_{0.67} \mathrm{BDT}\right)_{3} \cdot 17\left(\mathrm{H}_{2} \mathrm{O}\right) \cdot 0.5\left({ }^{i} \mathrm{PrOH}\right) \quad\left(\mathrm{H}_{2} \mathrm{BDT}=5,5^{\prime}-\right.$ (1,4-phenylene)bis $(1 H$-tetrazole $))\left(\mathrm{Fe}_{2}(\mathrm{BDT})_{3}\right),{ }^{17}$ and found that the single-crystal conductivity of this material is tunable over 5 orders of magnitude by varying the extent of $\mathrm{Fe}^{2+/ 3+}$ mixed valency. The results herein illustrate how inducing metalbased mixed valency in a MOF with continuous through-bond charge transport pathways results in electrical conductivity that is rationally tunable to values exceeding those of any other three-dimensional MOFs.

Single crystals of $\mathrm{Fe}_{2}(\mathrm{BDT})_{3}$ were isolated from a solvothermal reaction between $\mathrm{H}_{2} \mathrm{BDT}, \mathrm{FeSO}_{4} \cdot 7 \mathrm{H}_{2} \mathrm{O}$, and $\mathrm{NaSCN}$ in water and isopropyl alcohol $\left({ }^{i} \mathrm{PrOH}\right)$ under oxygen-free conditions. Powder X-ray diffraction (PXRD) analysis confirmed that the product was phase-pure and had the desired structure, containing one-dimensional $(\mathrm{Fe}-\mathrm{N}-\mathrm{N}-)_{\infty}$ chains extending in the [100] direction (Figure 1). Experimental indexing of a single crystal indicated that the long axis of the crystal corresponds to the crystallographic $a$ axis (Figure S1).

Orange-red crystals of as-synthesized $\mathrm{Fe}_{2}(\mathrm{BDT})_{3}$ gradually darken upon exposure to air over the course of several days, and progress to deep red and then black (Figure S2), with otherwise no structural distortion or degradation indicated by PXRD (Figure 1c). In comparison, crystals kept under oxygenfree conditions retain their original color over time. Further confirmation of structural integrity came through gas sorption studies: A nitrogen adsorption isotherm of air-exposed black $\mathrm{Fe}_{2}(\mathrm{BDT})_{3}$ upon activation under dynamic vacuum at $120{ }^{\circ} \mathrm{C}$ yielded an apparent Brunauer-Emmett-Teller (BET) surface area of $614(1) \mathrm{m}^{2} / \mathrm{g}$ (Figure S3), similar to the reported value for the Co analogue. ${ }^{18}$

Very dark colors or even black are commonly associated with mixed-valence compounds, ${ }^{19}$ as might be expected with $\mathrm{Fe}_{2}(\mathrm{BDT})_{3}$ from the oxidation of some $\mathrm{Fe}^{2+}$ sites to $\mathrm{Fe}^{3+}$. To ascertain whether these color changes and the presumed mixed

Received: April 3, 2018

Published: May 28, 2018 

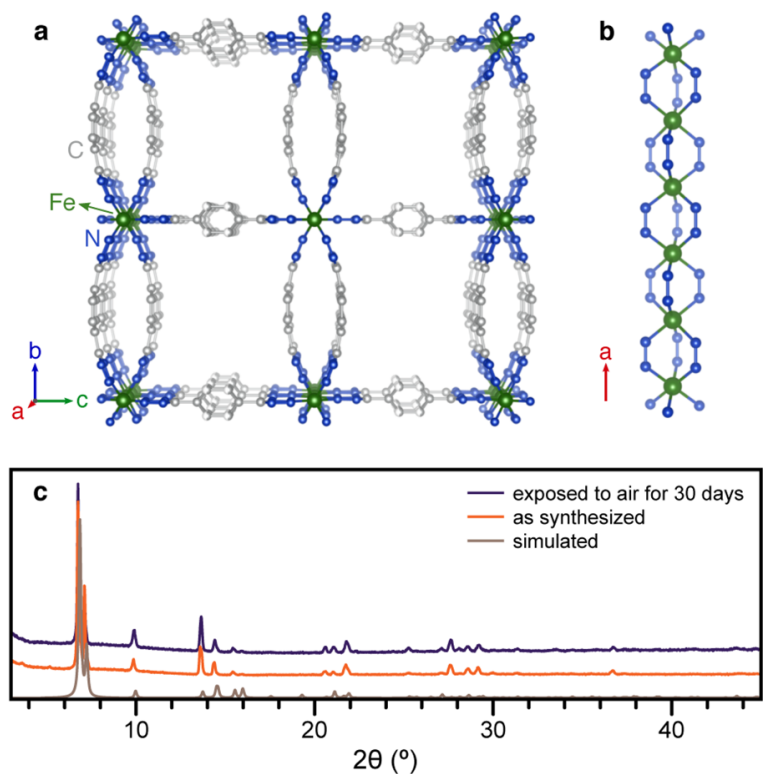

Figure 1. (a) Structure of $\mathrm{Fe}_{2}(\mathrm{BDT})_{3}$. (b) $(\mathrm{Fe}-\mathrm{N}-\mathrm{N}-)_{\infty}$ chains, which serve as the presumed charge transport pathways in this material. (c) Powder X-ray diffraction patterns of air-exposed, assynthesized, and simulated $\mathrm{Fe}_{2}(\mathrm{BDT})_{3}$.

valency led to improved charge transport, 11 two-probe devices $^{20}$ were fabricated by contacting single crystals of $\mathrm{Fe}_{2}(\mathrm{BDT})_{3}$ from six separate batches $(\sim 300-900 \mu \mathrm{m}$ in length) along the crystallographic $a$ axis. The average electrical conductivity of the as-synthesized red crystals was $6(2) \times 10^{-5}$ $\mathrm{S} / \mathrm{cm}$ at room temperature $(296 \mathrm{~K})$. Upon exposure to air, the conductivity invariably increased, exhibiting a remarkable correlation with the duration of exposure. Average conductivity values reached $0.3(2) \mathrm{S} / \mathrm{cm}$ after 7 days and $1.2(4) \mathrm{S} / \mathrm{cm}$ after 30 days, with a champion conductivity of $1.8 \mathrm{~S} / \mathrm{cm}$ (Figure 2).

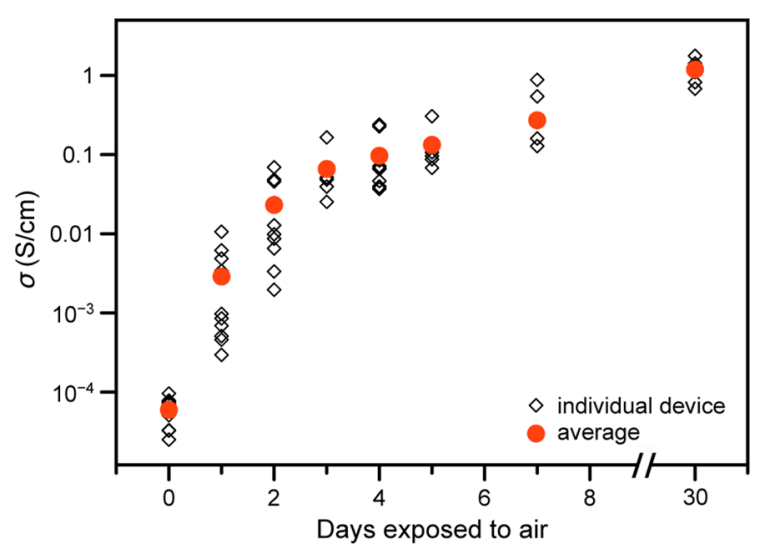

Figure 2. Conductivities of single-crystal devices of $\mathrm{Fe}_{2}(\mathrm{BDT})_{3}$ exposed to ambient atmosphere for different lengths of time measured under ambient conditions.

To the best of our knowledge, the conductivity of $\mathrm{Fe}_{2}(\mathrm{BDT})_{3}$ after 30 days in ambient atmosphere is the highest value reported to date for the single-crystal conductivity of any MOF material, ${ }^{1,3,21,22}$ as well as for a three-dimensionally connected MOF. ${ }^{6,8,11}$ Conductivity values remained constant thereafter, with no degradation observed in devices stored under ambient conditions for durations up to 7 months.
A variable-temperature (VT) conductivity measurement on a two-probe single-crystal device of $\mathrm{Fe}_{2}(\mathrm{BDT})_{3}$ that had been exposed to air for 30 days revealed semiconducting behavior (Figure 3). Fitting the data between 225 and $350 \mathrm{~K}$ to the

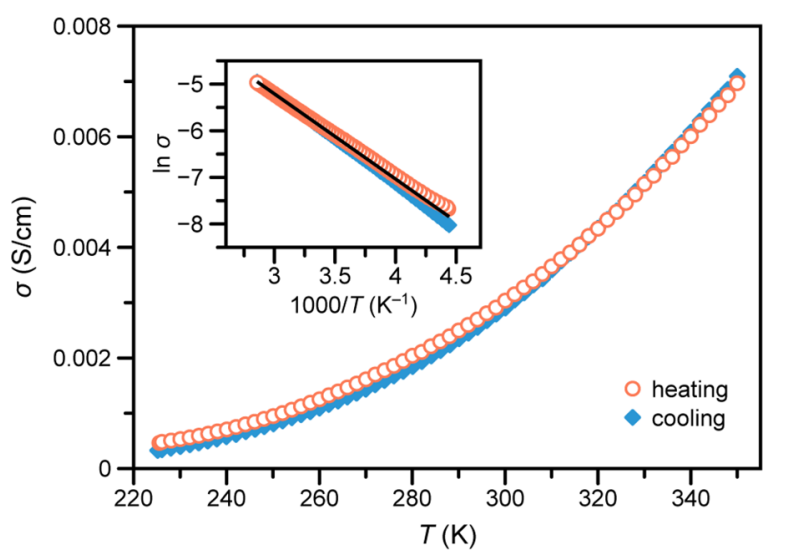

Figure 3. Variable-temperature conductivity measurement on a singlecrystal device of $\mathrm{Fe}_{2}(\mathrm{BDT})_{3}$. Inset: black line indicates fitting of the data to the Arrhenius equation, yielding an average value for $E_{\mathrm{a}}$ of 160 $\mathrm{meV}$.

Arrhenius equation $\sigma=\sigma_{0} \exp \left(-E_{\mathrm{a}} / k_{\mathrm{B}} T\right)$, where $\sigma$ is the electrical conductivity, $\sigma_{0}$ is a prefactor, $k_{\mathrm{B}}$ is the Boltzmann constant, and $T$ is the absolute temperature, yields an activation energy $\left(E_{\mathrm{a}}\right)$ of $160 \mathrm{meV}$ (Figure 3 inset). This value of $E_{\mathrm{a}}$ is among the lowest values reported for semiconducting MOFs or coordination polymers, and is consistent with low-energy defect states generated by charge doping upon air exposure. ${ }^{6-8,11}$ The lower conductivity values from this experiment, which was conducted under dynamic vacuum, compared to measurements in ambient conditions are consistent with previous observations for MOF single-crystal devices. ${ }^{20}$ For all measurements, linear $\mathrm{I}-\mathrm{V}$ curves were obtained (Figures S4 and S5).

Changes in the color of $\mathrm{Fe}_{2}(\mathrm{BDT})_{3}$ crystals along with the increasing conductivity with air exposure can be quantitatively probed optically. Fresh single crystals of $\mathrm{Fe}_{2}(\mathrm{BDT})_{3}$ were diluted with $\mathrm{BaSO}_{4}$, and diffuse reflectance UV-vis-nearinfrared (NIR) spectra were taken at different time points over the course of $48 \mathrm{~h}$ as the sample was exposed to the atmosphere (Figure 4). The bands at 300, 380, and $520 \mathrm{~nm}$ observed in

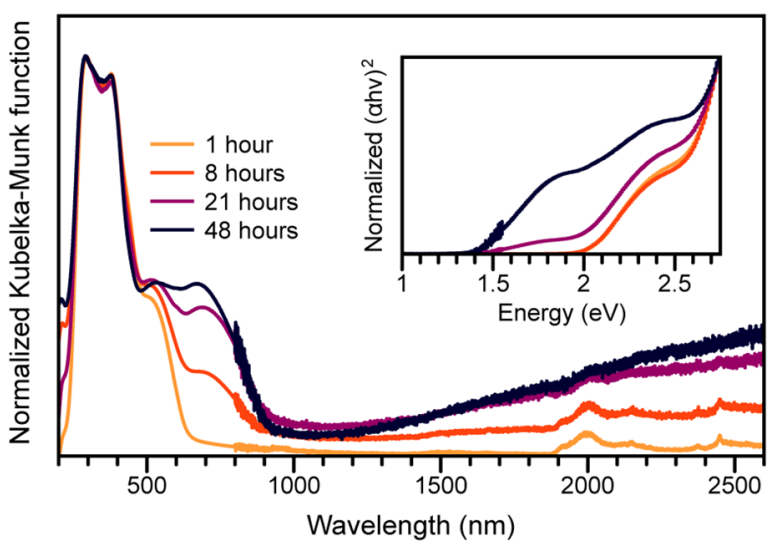

Figure 4. Diffuse reflectance UV-vis-NIR spectra of $\mathrm{Fe}_{2}(\mathrm{BDT})_{3}$ exposed to ambient atmosphere for different lengths of time. Inset: Tauc plot of the data. 
every spectrum are characteristic of low-spin (LS) $\mathrm{Fe}^{2+}$ centers octahedrally coordinated by tetrazole ligands. ${ }^{23,24}$ The transition at $300 \mathrm{~nm}$ corresponds to a ligand-to-metal charge transfer (LMCT), while the features at 380 and $520 \mathrm{~nm}$ can be assigned to $\mathrm{d}-\mathrm{d}$ transitions of LS Fe ${ }^{2+}\left({ }^{1} \mathrm{~A}_{1} \rightarrow{ }^{1} \mathrm{~T}_{2}\right.$ and ${ }^{1} \mathrm{~A}_{1} \rightarrow{ }^{1} \mathrm{~T}_{1}$, respectively). ${ }^{23,24}$

The evolution of the $\mathrm{Fe}_{2}(\mathrm{BDT})_{3}$ spectra as the material is exposed to atmosphere correlates with increasing $\mathrm{Fe}^{3+}$ concentrations. In particular, we assign the peak centered at $690 \mathrm{~nm}$, which grows in with longer air exposure times, to intervalence charge transfer (IVCT) between $\mathrm{Fe}^{2+}$ and $\mathrm{Fe}^{3+}$ centers. This feature is very similar to an IVCT band observed in Prussian blue, a canonical Class II mixed-valence compound in the Robin-Day classification. ${ }^{19,25}$ Furthermore, the broad feature observed in the NIR region after 21 and $48 \mathrm{~h}$ in air is tentatively assigned to polaronic transitions, which we attribute to increasing concentrations of charge carriers. The intensities of analogous features in conductive polymers correlate directly with doping levels. ${ }^{26,27}$

A Tauc plot of the Kubelka-Munk-transformed spectra reveals an optical bandgap of $2.0 \mathrm{eV}$ in as-synthesized $\mathrm{Fe}_{2}(\mathrm{BDT})_{3}$, as indicated from a linear fit to the onset of absorption (Figure 4 inset). In samples kept in air for 21 and 48 $\mathrm{h}$, the energy of the absorption onset decreases to $1.4 \mathrm{eV}$. The shift observed with increasing air exposure time indicates that midgap states are being populated in these samples and is consistent with the higher conductivity of crystals of $\mathrm{Fe}_{2}$ $(\mathrm{BDT})_{3}$ left in air for longer periods.

On the basis of transport and spectroscopic studies, $\mathrm{Fe}_{2}(\mathrm{BDT})_{3}$ can be described as a Class II material, defined by the coexistence of distinguishable localized valences along with measurable electronic coupling. ${ }^{19}$ Here, the $\mathrm{d}-\mathrm{d}$ transition bands in the optical data are characteristic of localized $\mathrm{Fe}^{2+}$ centers, while the IVCT features and transport properties indicate the presence of electronic coupling between mixedvalent $\mathrm{Fe}^{2+}$ and $\mathrm{Fe}^{3+}$ centers.

To further probe the oxidation and spin states of the iron centers in air-exposed $\mathrm{Fe}_{2}(\mathrm{BDT})_{3}$, we turned to ${ }^{57} \mathrm{Fe}$ Mössbauer spectroscopy. At $80 \mathrm{~K}$, a sample of $\mathrm{Fe}_{2}(\mathrm{BDT})_{3}$ exposed to ambient atmosphere for 12 days exhibited a broad signal that could be fitted with an isomer shift $\delta=0.378(3)$ $\mathrm{mm} / \mathrm{s}$ and quadrupole splitting $\Delta E_{\mathrm{Q}}=0.280(6) \mathrm{mm} / \mathrm{s}$ (Figure S6). This result is consistent with expected parameters for LS $\mathrm{Fe}^{2+}$ in an $\mathrm{O}_{h}$ environment ${ }^{28}$ and in line with experimental results for LS $\mathrm{Fe}^{2+}$ centers in similar ligand environments. ${ }^{16,29,30}$ As the Mössbauer signal from high-spin (HS) $\mathrm{Fe}^{3+}$ may overlap with that of $\mathrm{LS} \mathrm{Fe}^{2+}$, these data neither rule out nor confirm the presence of a small proportion of $\mathrm{HS} \mathrm{Fe}^{3+}$ centers. However, the data do indicate the absence of other iron spin states in the material, and also suggest at least partially localized $\mathrm{Fe}^{2+}$. The LS $\mathrm{Fe}^{2+}$ (or $\mathrm{HS} \mathrm{Fe}^{3+}$ ) assignment also agrees with the $\mathrm{Fe}-\mathrm{N}$ bond lengths of $1.948(3)$ and 1.961(3) $\AA$ from the published crystal structure. ${ }^{17}$

The importance of even a small concentration of $\mathrm{Fe}^{3+}$ centers is apparent from density functional theory (DFT) calculations, which revealed the intrinsic electronic band structure of $\mathrm{Fe}_{2}(\mathrm{BDT})_{3}$ (Figure 5). Importantly, the computed bandgap of the native $\mathrm{LS} \mathrm{Fe}^{2+}$ framework is $2.0 \mathrm{eV}$, in agreement with the optical bandgap obtained from electronic spectroscopy. The valence band (VB) dispersion width, about $380 \mathrm{meV}$, is also relatively large for a semiconducting MOF material. ${ }^{21,31}$ In addition, the density of states (DOS) indicates that the VB predominantly comprises $\mathrm{Fe}$ - and $\mathrm{N}$-centered orbitals, con-



Figure 5. Calculated band structure and density of states for partially oxidized $\mathrm{Fe}_{2}(\mathrm{BDT})_{3}$, modeled as a framework in which $1 / 8$ of the $\mathrm{Fe}^{2+}$ sites are replaced with $\mathrm{Fe}^{3+}$.

firming that the $(\mathrm{Fe}-\mathrm{N}-\mathrm{N}-)_{\infty}$ chains function as the primary charge transport pathways in $\mathrm{Fe}_{2}(\mathrm{BDT})_{3}$.

Air-exposed $\mathrm{Fe}_{2}(\mathrm{BDT})_{3}$ was modeled as a partially oxidized hypothetical material with a doubled unit cell wherein $1 / 8$ of the $\mathrm{Fe}^{2+}$ sites were replaced with $\mathrm{HS} \mathrm{Fe}^{3+}$. The $\mathrm{Fe}^{3+}$ defect unoccupied orbitals appear as midgap states, where the lowest energy state is separated from the VB maximum by only $\sim 60$ $\mathrm{meV}$. The location of these states is consistent with the higher conductivity and lower energy of the optical absorption onset experimentally observed upon air exposure. In particular, the proximity of the lowest energy $\mathrm{Fe}^{3+}$ state to the $\mathrm{VB}$ corroborates the small $E_{\mathrm{a}}$ obtained from VT conductivity measurements.

In conclusion, we have shown that the single-crystal conductivity of the MOF $\mathrm{Fe}_{2}(\mathrm{BDT})_{3}$ can be tuned over 5 orders of magnitude by varying the length of air exposure time, reaching the highest values yet for any three-dimensionally connected MOF. The partial oxidation of the material, resulting in $\mathrm{Fe}^{3+}$ defect states, is responsible for the high conductivity of the resulting mixed-valence MOF. The wide range of conductivities accessible on purpose in this material and the direct correlation between hole-doping, metal-based mixed valency, and conductivity demonstrated here serve as a blueprint for designing new conductive frameworks across diverse structures and compositions.

\section{ASSOCIATED CONTENT}

\section{S Supporting Information}

The Supporting Information is available free of charge on the ACS Publications website at DOI: 10.1021/jacs.8b03604.

Experimental and computational methods, and Figures S1-S7, showing crystal indexing results, images of devices, nitrogen adsorption isotherm, $I-V$ curves, Mössbauer spectrum, and cyclic voltammogram (PDF)

\section{AUTHOR INFORMATION}

\section{Corresponding Author}

*mdinca@mit.edu 


\section{ORCID 우}

Lei Sun: 0000-0001-8467-6750

Christopher H. Hendon: 0000-0002-7132-768X

Mircea Dincă: 0000-0002-1262-1264

\section{Notes}

The authors declare no competing financial interest.

\section{ACKNOWLEDGMENTS}

The experimental work was supported by the U.S. Department of Energy, Office of Science, Office of Basic Energy Sciences (DE-SC0018235). L.S.X. thanks the National Science Foundation for support through the Graduate Research Fellowship Program (1122374). This work used the Extreme Science and Engineering Discovery Environment (XSEDE), which is supported by the NSF (ACI-1053575). We thank Dr. Peter Müller and Dr. Jonathan Becker for assistance with crystal indexing experiments, Dr. Robert Day and Grigorii Skorupskii for assistance with variable-temperature conductivity measurements, and Dr. Jin-Hu Dou for helpful discussions.

\section{REFERENCES}

(1) Sun, L.; Campbell, M. G.; Dincă, M. Angew. Chem., Int. Ed. 2016, $55,3566-3579$.

(2) Narayan, T. C.; Miyakai, T.; Seki, S.; Dincă, M. J. Am. Chem. Soc. 2012, 134, 12932-12935.

(3) Hmadeh, M.; Lu, Z.; Liu, Z.; Gándara, F.; Furukawa, H.; Wan, S.; Augustyn, V.; Chang, R.; Liao, L.; Zhou, F.; Perre, E.; Ozolins, V.; Suenaga, K.; Duan, X.; Dunn, B.; Yamamoto, Y.; Terasaki, O.; Yaghi, O. M. Chem. Mater. 2012, 24, 3511-3513.

(4) Sheberla, D.; Sun, L.; Blood-Forsythe, M. A.; Er, S.; Wade, C. R.; Brozek, C. K.; Aspuru-Guzik, A.; Dincă, M. J. Am. Chem. Soc. 2014, 136, 8859-8862.

(5) Kambe, T.; Sakamoto, R.; Kusamoto, T.; Pal, T.; Fukui, N.; Hoshiko, K.; Shimojima, T.; Wang, Z.; Hirahara, T.; Ishizaka, K.; Hasegawa, S.; Liu, F.; Nishihara, H. J. Am. Chem. Soc. 2014, 136, $14357-14360$

(6) Darago, L. E.; Aubrey, M. L.; Yu, C. J.; Gonzalez, M. I.; Long, J. R. J. Am. Chem. Soc. 2015, 137, 15703-15711.

(7) DeGayner, J. A.; Jeon, I.-R.; Sun, L.; Dincă, M.; Harris, T. D. J. Am. Chem. Soc. 2017, 139, 4175-4184.

(8) Takaishi, S.; Hosoda, M.; Kajiwara, T.; Miyasaka, H.; Yamashita, M.; Nakanishi, Y.; Kitagawa, Y.; Yamaguchi, K.; Kobayashi, A.; Kitagawa, H. Inorg. Chem. 2009, 48, 9048-9050.

(9) Gándara, F.; Uribe-Romo, F. J.; Britt, D. K.; Furukawa, H.; Lei, L.; Cheng, R.; Duan, X.; O’Keeffe, M.; Yaghi, O. M. Chem. - Eur. J. 2012, 18, 10595-10601.

(10) Sun, L.; Hendon, C. H.; Minier, M. A.; Walsh, A.; Dincă, M. J. Am. Chem. Soc. 2015, 137, 6164-6167.

(11) Kobayashi, Y.; Jacobs, B.; Allendorf, M. D.; Long, J. R. Chem. Mater. 2010, 22, 4120-4122.

(12) Talin, A. A.; Centrone, A.; Ford, A. C.; Foster, M. E.; Stavila, V.; Haney, P.; Kinney, R. A.; Szalai, V.; El Gabaly, F.; Yoon, H. P.; Léonard, F.; Allendorf, M. D. Science 2014, 343, 66-69.

(13) Wang, H.-Y.; Ge, J.-Y.; Hua, C.; Jiao, C.-Q.; Wu, Y.; Leong, C. F.; D’Alessandro, D. M.; Liu, T.; Zuo, J.-L. Angew. Chem., Int. Ed. 2017, 56, 5465-5470.

(14) Wiers, B. M. Charge Transport in Metal-Organic Frameworks.

Ph.D. Thesis, University of California, Berkeley, 2015.

(15) Murase, R.; Leong, C. F.; D’Alessandro, D. M. Inorg. Chem. 2017, 56, 14373-14382.

(16) Sun, L.; Hendon, C. H.; Park, S. S.; Tulchinsky, Y.; Wan, R.; Wang, F.; Walsh, A.; Dincă, M. Chem. Sci. 2017, 8, 4450-4457.

(17) Yan, Z.; Li, M.; Gao, H.-L.; Huang, X.-C.; Li, D. Chem. Commun. 2012, 48, 3960-3962.

(18) Ouellette, W.; Prosvirin, A. V.; Whitenack, K.; Dunbar, K. R.; Zubieta, J. Angew. Chem., Int. Ed. 2009, 48, 2140-2143.
(19) Robin, M. B.; Day, P. Mixed Valence Chemistry-A Survey and Classification. In Advances in Inorganic Chemistry and Radiochemistry; Academic Press, 1968; pp 247-422.

(20) Sun, L.; Park, S. S.; Sheberla, D.; Dincă, M. J. Am. Chem. Soc. 2016, 138, 14772-14782.

(21) Park, S. S.; Hontz, E. R.; Sun, L.; Hendon, C. H.; Walsh, A.; Van Voorhis, T.; Dincă, M. J. Am. Chem. Soc. 2015, 137, 1774-1777.

(22) Zeng, M.-H.; Wang, Q.-X.; Tan, Y.-X.; Hu, S.; Zhao, H.-X.; Long, L.-S.; Kurmoo, M. J. Am. Chem. Soc. 2010, 132, 2561-2563.

(23) Buchen, T.; Gütlich, P. Chem. Phys. Lett. 1994, 220, 262-266.

(24) Absmeier, A.; Bartel, M.; Carbonera, C.; Jameson, G. N. L.; Weinberger, P.; Caneschi, A.; Mereiter, K.; Létard, J.-F.; Linert, W. Chem. - Eur. J. 2006, 12, 2235-2243.

(25) Robin, M. B. Inorg. Chem. 1962, 1, 337-342.

(26) Chung, T.-C.; Kaufman, J. H.; Heeger, A. J.; Wudl, F. Phys. Rev. B: Condens. Matter Mater. Phys. 1984, 30, 702-710.

(27) Brédas, J. L.; Scott, J. C.; Yakushi, K.; Street, G. B. Phys. Rev. B: Condens. Matter Mater. Phys. 1984, 30, 1023-1025.

(28) Gütlich, P.; Eckhard, B.; Trautwein, A. X. Mössbauer Spectroscopy and Transition Metal Chemistry: Fundamentals and Applications; Springer-Verlag: Berlin, 2011.

(29) Decurtins, S.; Gütlich, P.; Köhler, C. P.; Spiering, H.; Hauser, A. Chem. Phys. Lett. 1984, 105, 1-4.

(30) Reed, D. A.; Keitz, B. K.; Oktawiec, J.; Mason, J. A.; Runčevski, T.; Xiao, D. J.; Darago, L. E.; Crocellà, V.; Bordiga, S.; Long, J. R. Nature 2017, 550, 96-100.

(31) Gao, J.; Miao, J.; Li, P.-Z.; Teng, W. Y.; Yang, L.; Zhao, Y.; Liu, B.; Zhang, Q. Chem. Commun. 2014, 50, 3786-3788. 